\title{
Prognostic Value of the Neutrophil-Lymphocyte and Platelet- Lymphocyte Ratios in Predicting One-Year Mortality in Patients with Hip Fractures and Aged Over 60 Years
}

\author{
Emine Emektar, Şeref Kerem Çorbacıoğlu, Seda Dağar, Hüseyin Uzunosmanoğlu, Tuba Şafak, Yunsur Çevik \\ Clinic of Emergency Medicine, Keçiören Training and Research Hospital, Ankara, Turkey
}

Cite this article as: Emektar E, Çorbacıoğlu ŞK, Dağar S, Uzunosmanoğlu H, Şafak T, Çevik Y. Prognostic Value of the NeutrophilLymphocyte and Platelet-Lymphocyte Ratios in Predicting One-Year Mortality in Patients with Hip Fractures and Aged Over 60 Years. Eurasian J Emerg Med 2017; 16: 165-70.

\begin{abstract}
Aim: In this study, we aimed to determine the effect of neutrophil-lymphocyte ratio (NLR) and platelet-lymphocyte ratio (PLR) on one-year mortality in patients with hip fractures and aged over 60 years.

Materials and Methods: The S72.00, S72.10, and S72.20 codes were screened according to International Classification of Disease-10, and 560 patients were included as cases of hip fractures. Blood counts on admission and clinical data were obtained from medical data. Predictors of one-year mortality were evaluated.

Results: In total, 116 out of 560 patients (20.7\%) included in the study died during the one-year follow-up. When the patients' characteristics were compared according to one-year mortality (survivor and non-survivor groups), significant differences were detected for age, lymphocyte count, NLR, and PLR ( $\mathrm{p}<0.05$ ). When a Cox regression model was created to assess the factors predicting one-year mortality, the hazard ratios of NLR and PLR were 1.059 (1.022-1.097, $\mathrm{p}=0.002$ ) and $0.997(0.994-0999, \mathrm{p}=0.01)$, respectively.

Conclusion: In the study, in predict mortality among patients aged over 60 years and who had hip fractures, the NLR and PLR were observed to be higher in the survivor group than in the non-survivor group. However, when the specificity of these values is considered, it is obvious that they are not sufficiently reliable for clinical use.
\end{abstract}

Keywords: Hip fracture, neutrophil-lymphocyte ratio, platelet-lymphocyte ratio, one-year mortality

\section{Introduction}

Since the human lifespan has increased in recent years, there has been an increase in the geriatric population. Hip fractures, which are commonly seen among the elderly, are injuries with high mortality and morbidity rates, resulting due to the limited physiological reserves of the elderly, their preoperative medical conditions, trauma, and major surgical combinations (1,2). The average lifespan among the elderly who received treatment for hip fractures is shorter than the lifespan of those who did not receive treatment in the same age group (3). Except for the direct effect of trauma, reactions, such as systemic inflammatory response syndrome, might develop in pa- tients with hip fractures in a manner similar to that for multi-trauma patients; this is considered a significant mortality factor for the patient group involved. Therefore, considering the factors that might be related to the degree of the inflammatory response in patients with hip fractures could give an idea regarding mortality (4).

The white blood cell (WBC) count is regarded a well-defined inflammatory indicator and/or stress indicator, whereas the neutrophillymphocyte ratio (NLR), which is calculated through the division of absolute neutrophil count by absolute lymphocyte count, is asserted to be a new indicator of the inflammatory response. A high correlation has been detected between the NLR and acute coronary syndrome, non-ST myocardial infarcts, ischemic and hemorrhag-

\section{Correspondence to: Emine Emektar e-mail: emineakinci@yahoo.com}


ic strokes, pulmonary embolisms, and several types of cancer (57), while the platelet-lymphocyte ratio (PLR) is calculated through the division of absolute platelet count by lymphocyte count. The PLR has been claimed to have potential as a marker to help identify thrombotic activity and inflammation in certain oncological and cardiac diseases $(8,9)$. In previous studies, a number of factors in hip fractures that could lead to mortality have been analyzed. However, there are a limited studies show that the subtypes of leukocyte and thrombocyte counts, especially $\mathrm{NL}$ and $\mathrm{PL}$, are associated with severe clinical conditions and mortality in major surgical procedures in the literature (10-12). In this study, we aimed to determine the prognostic value of the NLR and PLR on one-year mortality in patients who have hip fractures and aged over 60 years.

\section{Materials and Methods}

\section{Study population}

This retrospective, case-control study was designed after obtaining approval by the local ethics committee. The diagnostic codingof patients who were admitted to the emergency department (ED) of a training and research hospital between January 2009 and March 2015 was screened from the electronic database of the hospital. The diagnostic coding was performed by scanning the International Classification of Disease-10 (ICD-10) codes on patients with the S72.00 (femur neck fracture, closed), S72.10 (pertrochanteric fracture, closed), and S72.20 (subtrochanteric fracture, closed) codes. We obtained death data of patients from the national death notification system. Those with high-energy trauma, a hematological disease, an infectious and inflammatory disease, a recent myocardial infarction, severe renal disease (glomerular filtration rate $<30 \mathrm{~mL} / \mathrm{min}$ ), severe liver disease, immunosuppression, and a history of malignancy and those aged under 60 years were excluded from the study. Overall, 694 patients were found to have the three ICD codes (S72.00, S72.10, S72.20); 134 patients were excluded ( 56 patients aged $<60$ years, 27 patients had missing data, 18 had high-energy trauma, 2 had active malignancy, 28 had chronic renal failure, and 3 had severe liver disease). Finally, 560 patients were included in the study for statistical analyses (Figure 1).

\section{Data collection}

The demographic data of the patients, whole blood count parameters obtained on admission [such as WBC count, NLR, red blood cell distribution width (RDW), hemoglobin level, platelet count, PLR, and mean platelet volume (MPV)], fracture types of the patients, duration of hospital stay, and comorbidities and their outcomes at the hospital (discharge, death) were recorded in study forms. It was obtained from Public Health Association death notification system whether patients are survived at present. The patients were divided into two groups as survivor and non survivor according to one year mortality.

\section{Laboratory parameters}

The laboratory results were evaluated according to the first venous blood samples taken on admission to the ED. Total blood cell counts and its subtypes were analyzed using an automated blood cell counter (Cell-dyn, 3700, Abbott, USA). The NLR was calculated as the ratio of the neutrophil count to the lymphocyte count, and the PLR was calculated as the ratio of platelet count to lymphocyte count.

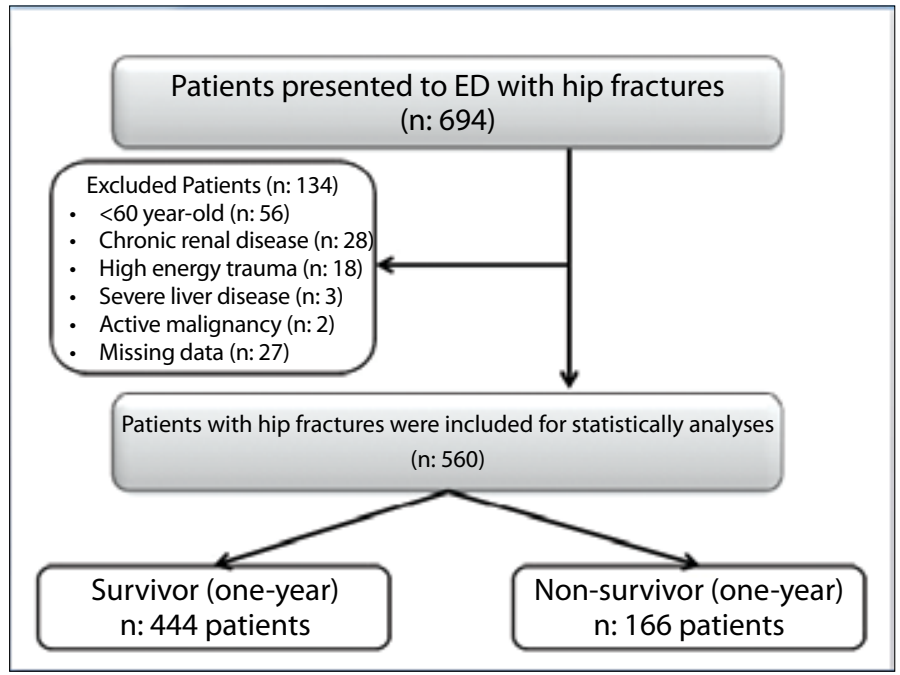

Figure 1. Flow chart of patients

Table 1. Demographics and some laboratory findings of the patients [median (IQR 25\%-75\%)]

\begin{tabular}{|c|c|}
\hline Age (years) & $80(74-85)$ \\
\hline Sex (female), n (\%) & $348(62.1)$ \\
\hline \multicolumn{2}{|l|}{ Comorbidities, n (\%) } \\
\hline Hypertension & $264(47.1)$ \\
\hline Congestive heart failure & $24(4.3)$ \\
\hline Chronic renal disease & $27(4.8)$ \\
\hline Diabetes mellitus & $121(21.6)$ \\
\hline Coronary artery disease & $98(17.5)$ \\
\hline Hemoglobin level (g/dL) & $11.8(10.5-13.1)$ \\
\hline WBC count $\left(10^{3} / \mu \mathrm{L}\right)$ & $9.9(7.8-12.1)$ \\
\hline Neutrophil count $\left(10^{3} / \mu \mathrm{L}\right)$ & $7.8(5.8-10.3)$ \\
\hline Lymphocyte count $\left(10^{3} / \mu \mathrm{L}\right)$ & $1.2(0.8-1.6)$ \\
\hline Red blood cell distribution width (\%) & $14.9(13.9-16.4)$ \\
\hline Platelet count $\left(10^{3} / \mu \mathrm{L}\right)$ & $212(169-257)$ \\
\hline Mean platelet volume (fL) & $8.3(7.7-9)$ \\
\hline NLR & $6.7(4-11)$ \\
\hline PLR & $181(126-256)$ \\
\hline \multicolumn{2}{|l|}{ Type of fracture, n (\%) } \\
\hline Head & $9(1.6)$ \\
\hline Neck & $424(75.7)$ \\
\hline Perthrochanteric & $127(22,7)$ \\
\hline 30-day mortality, n (\%) & $27(4.8)$ \\
\hline One-year mortality, n (\%) & $116(20.7)$ \\
\hline
\end{tabular}

\section{Statistical analysis}

Statistical analyses were performed using Statistical Package for the Social Sciences 15.0 (SPSS Inc.; Chicago, IL, USA). Demograph- 
Table 2. Patients' characteristics according to long-term (one-year) mortality [median (IQR 25\%-75\%)]

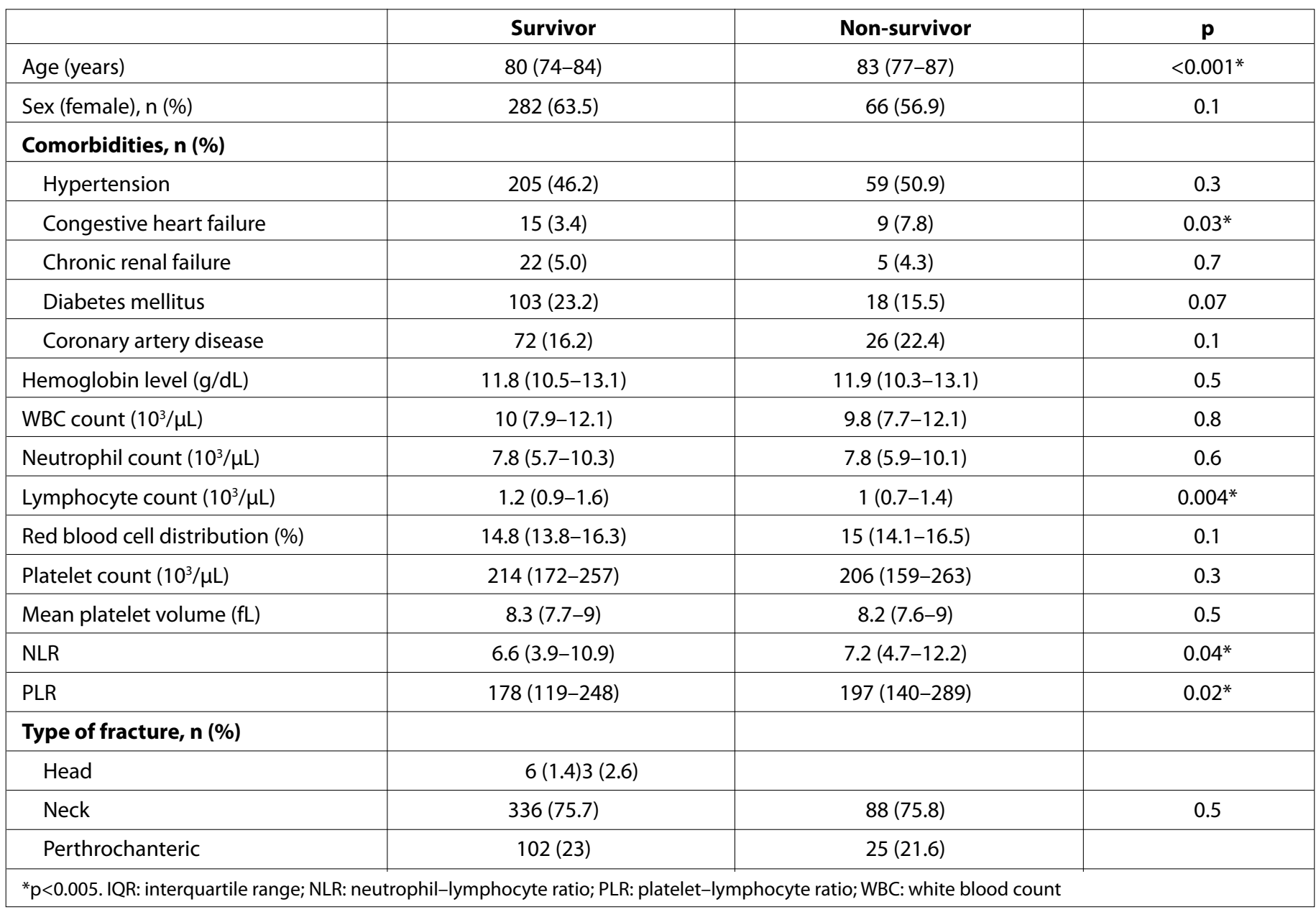

ic data related to the patients were expressed as number, percentage, median values, and interquartile range (IQR, 25\%-75\%). The Kolmogorov-Smirnov test was used to assess the normal distribution of the variables. Non-parametric parameters were analyzed using the Mann-Whitney $U$ test. To determine the cut off values of the NLR and PLR between the survivor and non-survivor groups, a receiver operating characteristic (ROC) curve was generated, and the area under curve (AUC) was calculated. Multivariate Cox regression models were used to evaluate the relationship of oneyear mortality with the NLR and PLR. Age, sex, comorbidities, hemoglobin level, WBC count, lymphocyte count, neutrophil count, MPV, RDW, and the type of fracture were included multivariate Cox regression model. Finally, for two groups, which were created according to the cut off values of NLR and PLR, survival rates were calculated using the Kaplan-Meier curve for one-year mortality. The $95 \%$ confidence intervals $(95 \% \mathrm{Cls})$ were calculated whenever appropriate, and a $\mathrm{p}$ value of $<0.05$ was considered statistically significant.

\section{Results}

A total of 560 patients diagnosed with femur fractures were included in the study for statistical analyses; 348 patients (62.1\%) were women and median age of all patients was 80 years (IQR, 25\%-75\%, 74-85). The median NLR and PLR were 6.7 (4-11) and 181 (126-256), respec- tively. In total, 27 patients (4.8\%) died within 30 days and 116 (20.7\%) died within 1 year. The demographics and some laboratory results of all patients are shown in Table 1.

When patients' characteristics were compared according to the one-year mortality of patients (survivor-non-survivor), significant differences were detected for age, lymphocyte count, the NLR, and the PLR $(p<0.05)$. While the median NLR was $6.6(3.9-10.9)$ in the survivor group, it was 7.2 (4.7-12.2) in the non-survivor group $(p=0.04)$. While the median PLR was $178(119-248)$ in the survivor group, it was $197(140-289)$ in the non-survivor group $(p=0.02)$ (Table 2).

\section{Laboratory parameters}

The cutoff NLR was obtained regarding the differences between the survivor and non-survivor groups using ROC analysis. For the NLR, the AUC was estimated as $0.56(95 \% \mathrm{Cl}, 0.50-0.61)$, and the best cutoff NLR was 3.9 (sensitivity, $80 \%$; specificity, 25\%) (Table 3, Figure 2).

When survival rates were calculated using the Kaplan-Meier curve for one-year mortality according to cutoff NLR (3.9), the estimated mean of survival day was $314(95 \% \mathrm{Cl}, 295-332)$ in patients with an NLR of $<3.9$ and the estimated mean of survival day was 306 (95\% $\mathrm{Cl}, 295-316)$ in patients with an NLR of $>3.9$. However, the difference 
Table 3. Prediction performance of the NLR and PLR for long-term (one-year) mortality

\begin{tabular}{|l|c|c|}
\hline & $\begin{array}{c}\text { NLR } \\
\text { (Cut-off: 3.9) }\end{array}$ & $\begin{array}{c}\text { PLR } \\
\text { (Cut-off: 131) }\end{array}$ \\
\hline Sensitivity & $80(71-87)$ & $80(71-87)$ \\
\hline Specificity & $25(20-28) 29(25-33)$ & \\
\hline Positive likelihood ratio & $1.06(0.96-1.18)$ & $1.13(1.02-1.26)$ \\
\hline Negative likelihood ratio & $0.81(0.5-1.21)$ & $0.68(0.4-1)$ \\
\hline Accuracy & $56(50-61)$ & $56(50-62)$ \\
\hline NLR: neutrophil-lymphocyte ratio; PLR: platelet-lymphocyte ratio \\
\hline
\end{tabular}

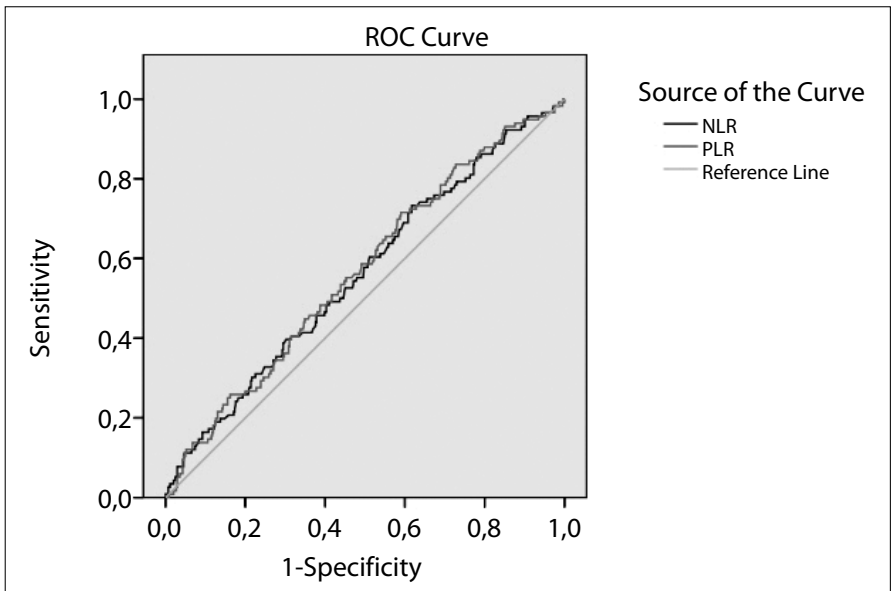

Figure 2. ROC curve of the NLR and PLR to predict mortality NLR: neutrophil-lymphocyte ratio; PLR: platelet-lymphocyte ratio; ROC: receiver operating characteristic

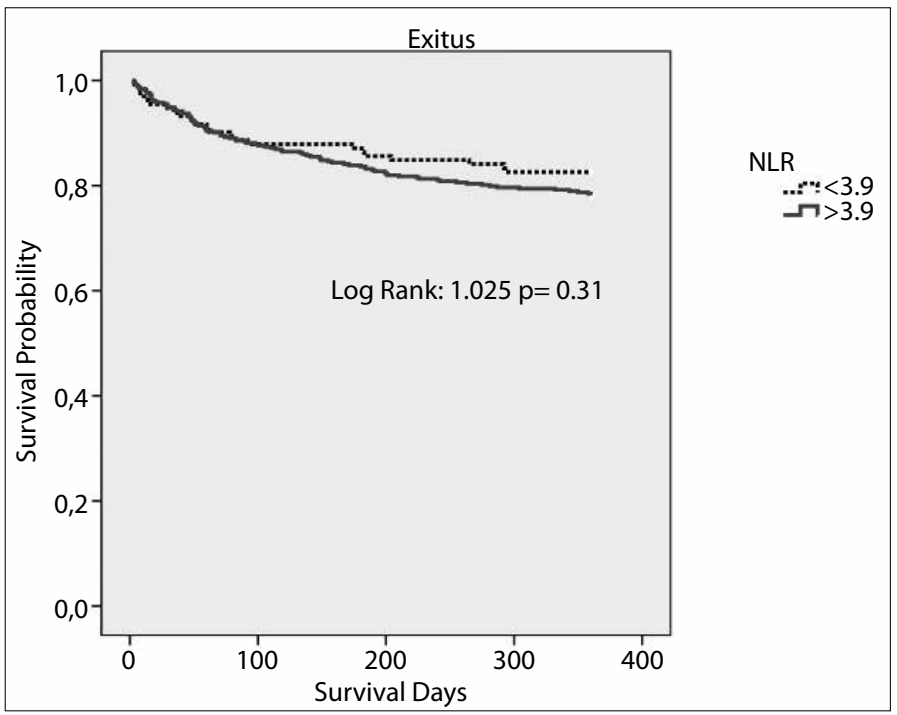

Figure 3. Comparison of Kaplan-Meier survival curves of the NLR NLR: neutrophil-lymphocyte ratio

between the groups was not statistically significant (log-rank test, 1.025; $\mathrm{p}=0.3$ ) (Figure 3).

When the Cox regression model was created to assess the factors predicting one-year mortality, the hazard ratio (HR) of the NLR was 1.059 (1.022-1.097; $\mathrm{p}=0.002$; Table 4).
Table 4. Cox regression model to predict long-term (one-year) mortality

\begin{tabular}{|l|c|c|c|}
\hline & Wald & p value & HR (95\% Cl) \\
\hline Age (years) & 8.89 & 0.03 & $1.03(1.01-1.06)$ \\
\hline Sex & 1.15 & 0.2 & $0.7(0.5-1.1)$ \\
\hline Comorbidities, $\mathrm{n}(\%)$ & & & \\
\hline \multicolumn{1}{|c|}{ Hypertension } & 1.06 & 0.3 & $1.2(0.8-1.6)$ \\
\hline \multicolumn{1}{|c|}{ Congestive heart failure } & 2.24 & 0.1 & $1.7(0.8-3.5)$ \\
\hline \multicolumn{1}{|c|}{ Chronic renal failure } & 0.03 & 0.8 & $0.9(0.3-2.2)$ \\
\hline \multicolumn{1}{|c|}{ Diabetes mellitus } & 4.04 & 0.04 & $0.5(0.3-0.9)$ \\
\hline \multicolumn{1}{|c|}{ Coronary artery disease } & 2.95 & 0.08 & $1.4(0.9-2.3)$ \\
\hline Hemoglobin level (g/dL) & 0.001 & 0.9 & $0.9(0.8-1.1)$ \\
\hline WBC count (10 $/ \mu \mathrm{LL})$ & 0.58 & 0.4 & $1(1-1)$ \\
\hline Neutrophil count $\left(10^{3} / \mu \mathrm{L}\right)$ & 0.08 & 0.7 & $1(1-1)$ \\
\hline Lymphocyte count $\left(10^{3} / \mu \mathrm{L}\right)$ & 0.40 & 0.52 & $1(1-1)$ \\
\hline Red blood cell distribution $(\%)$ & 0.83 & 0.36 & $1.04(0.9-1.1)$ \\
\hline Platelet count $\left(10^{3} / \mu \mathrm{L}\right)$ & 3.55 & 0.06 & $1(1-1)$ \\
\hline Mean platelet volume (fL) & 0.17 & 0.67 & $0.9(0.7-1.1)$ \\
\hline NLR & 9.97 & 0.002 & $1.05(1.02-1.09)$ \\
\hline PLR & 6.01 & 0.01 & $0.997(0.994-0999)$ \\
\hline Type of fracture & 1.04 & 0.7 & $2.2(0.4-11.5)$ \\
\hline $\begin{array}{l}\text { Cl: confidence interval; HR: hazard ratio; NLR: neutrophil-lymphocyte ratio; } \\
\text { PLR: platelet-lymphocyte ratio; WBC: white blood cell }\end{array}$ \\
\hline
\end{tabular}

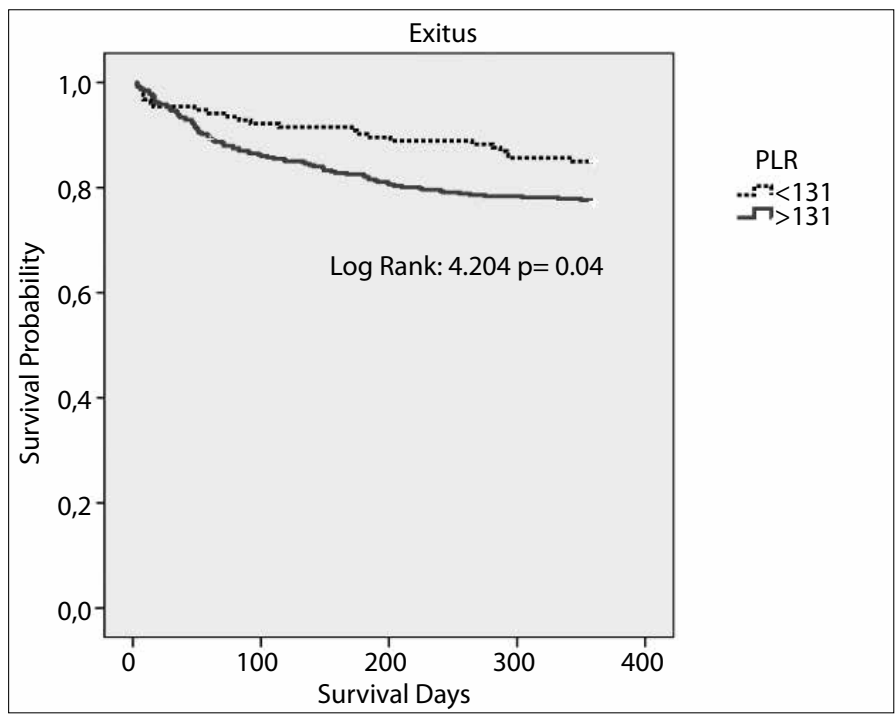

Figure 4. Comparison of Kaplan-Meier survival curves of the PLR PLR: platelet-lymphocyte ratio

\section{Platelet-lymphocyte ratio}

The cutoff PLR was obtained regarding the differences between the survivor and non-survivor groups by ROC analysis. For the PLR, the AUC was measured as $0.56(95 \% \mathrm{Cl}, 0.50-0.62)$, and the best cutoff PLR was 131 (sensitivity, 80\%; specificity 30\%) (Table 3, Figure 2). 
When survival rates were calculated using the Kaplan-Meier curve for one-year mortality according to the cutoff PLR (131), the estimated mean of the survival day was $325(95 \% \mathrm{Cl}, 310-340)$ in patients with a PLR of $<131$ and the estimated mean of survival day was $301(95 \% \mathrm{Cl}, 290$ 312 ) in patients with a PLR of $>131$. The difference between the groups was statistically significant (log-rank test, 4.204; $p=0.04$ ) (Figure 4).

When the Cox regression model was created to assess the factors predicting one-year mortality, the HR of the PLR was 0.997 (0.9940999, $\mathrm{p}=0.01$ ) (Table 4).

\section{Discussion}

In the study, wherein we researched the NLR and PLR for predicting mortality among patients aged over 60 years and who had hip fractures, both NLR and PLR were observed to be higher in the survivor group than in the non-survivor group. However, when the specificity of these values is considered, it is obvious that these values are not sufficiently reliable for clinical use. Likewise, according to the cut off values, which were determined using ROC analysis, when the survey of the patient groups were evaluated using Kaplan-Meier life analysis in terms of one-year mortality, there were no differences in the survey based on the NLR, whereas there was a statistical difference based on the PLR. However, we believe that this difference does not contribute significantly to clinical use in practice.

The markers for inflammation were considered in a very large disease group $(13,14)$. In an effort to study the state of the inflammatory response in the body and to what extent it is stimulated, biomarkers such as WBCs, acute-phase reactants, and adhesion molecules and cytokines were used. In routine practice, the WBC count is used for the diagnosis and follow-up of diseases and is noted in many scoring systems (13). WBCs play an important role in the systemic inflammatory response. Jilma et al. (14) studied changes in the types of WBC after inflammation and found that the neutrophils in circulation increased in number and that the number of monocytes and lymphocytes decreased. In recent years, the NLR has been regarded as a parameter that shows a high level of neutrophils, which is indicative of an acute inflammatory response, and the poor health condition as well as the negative effects of the low level of lymphocytes, which reflect physiological stress (15). In the previously conducted studies, the NLR has been reported as a new cardiovascular risk factor $(16,17)$. However, there are few studies in which risk analyses of patients were considered in the preoperative period of the surgical population. In the study by Vaughan-Shaw et al. (10), it was claimed that the NLR could be used as an independent predictor in the survey prediction among geriatric patients who require emergency abdominal surgery. Hip fractures mostly affect the geriatric population that often has more than one health problem. On average, an old person usually has more than one disease $(18,19)$. Among these diseases, cardiac, respiratory, and cerebral diseases and malignancies are largely responsible for mortality and morbidity in the geriatric population $(20,21)$. Further, these diseases are associated with chronic inflammation. This highlights the relationship between the NLR and the progression of the diseasein patients with chronic illnesses. Forget et al. (11) evaluated the NLR after surgery for hip fractures. They researched the relationships between patients' NLRs on admission and postoperatively on the second and fifth days with adverse clinical events in the hospital and mortality after discharge and suggested that NLR alone is a risk factor but that it cannot be used as a predictor for mortality. In contrast, a study by Sedlar et al. (12) focused on the effect of early postoperative period and subacute inflammatory response [WBC count, NLR, C-reactive protein level, interleukin-6 level, and soluble adhesion molecule level] on the long-term mortality but did not to confirm the effect of acute inflammatory response. Our study is based on the baseline NLR that we obtained when patients were admitted to the ED in the preoperative period, and we do not consider that the NLR can be used as an indicator in predicting mortality.

Increased platelet activity is closely associated with atherosclerosis and thromboembolic states. It has been suggested that the PLR is a new indicator showing chronic inflammation. In particular, the PLR has been introduced as a potential marker to determine excess thrombotic activity and inflammation in oncologic and cardiac disorders $(22,23)$. In several recent studies, it has been suggested that the PLR is associated with major adverse cardiovascular outcomes and that it is an independent marker of mortality in some oncological diseases $(24,25)$. In a study by Turkmen et al. (26), the PLR was shown to be superior to the NLR in predicting the severity of inflammation. Similarly, Neofytou et al. (27) suggested that the PLR was superior in diagnosing colorectal cancer. To our knowledge, our study is the first to determine the predictive value of the PLR and hip fractures. Although we found a statistically significant difference with the PLR in living analyses in terms of one-year mortality, we believe that this difference (estimated mean of survival day; survivor for 325 days, non-survivor for 301 days) will not make a significant clinical contribution with regard to hip fractures.

\section{Study limitations}

Our study has several limitations. It is a single-center retrospective study, and data were obtained from patient files. The postoperative hematological parameters of the patients were not considered. Repetitive measurements of the NLR and PLR were not performed. The inflammatory process is complex, and other inflammatory parameters were not evaluated in this study. We used a single blood sample to calculate the NLR and included all-cause mortality as our endpoint. Considering the retrospective nature of our analysis, the results should be regarded only for generating a hypothesis and need to be confirmed in prospective trials.

\section{Conclusion}

It is important to identify new risk factors for mortality predictions after hip fractures in the geriatric age group. The NLR and PLR are simple measures, do not require additional expenses, and are inexpensive, universally available, rapidly accessible, and routine parameters. We found that in patients with a hip fracture, the NLR and PLR measured at admission were higher in the survivor group than in the non-survivor group. However, we believe that this difference does not make a significant contribution for use in clinical practice.

Ethics Committee Approval: Ethics committee approval was received for this study from the ethics committee of Keçiören Training and Research Hospital.

Informed Consent: Written informed consent was not obtained because of retrospective study. 
Peer-review: Externally peer-reviewed.

Conflict of Interest: No conflict of interest was declared by the authors.

Financial Disclosure: The authors declared that this study has received no financial support.

\section{References}

1. Vidan M, Serra JA, Moreno C, Riquelme G, Ortiz J. Efficacy of a comprehensive geriatric intervention in older patients hospitalized for hip fracture: a randomized, controlled trial. J Am Geriatr Soc 2005; 53: 1476-82. [CrossRef]

2. Panula J, Pihlajamäki $H$, Mattila VM, Jaatinen $P$, Vahlberg $T$, Aarnio $P$, et al. Mortality and cause of death in hip fracture patients aged 65 or older: a population-based study. BMC Musculoskelet Disord 2011; 12: 105. [CrossRef]

3. Ariza-Vega P, Kristensen MT, Martín-Martín L, Jiménez-Moleón JJ. Predictors of long-term mortality in older people with hip fracture. Arch Phys Med Rehabil 2015; 96: 1215-21. [CrossRef]

4. Hu F, Jiang C, Shen J, Tang P, Wang Y. Preoperative predictors for mortality following hip fracture surgery: a systematic review and meta-analysis. Injury 2012; 43: 676-85. [CrossRef]

5. Soylu K, Gedikli Ö, Ekşi A, Avcıoğlu Y, Soylu A, Yüksel S, et al. Neutrophil-to-lymphocyte ratio for the assessment of hospital mortality in patients with acute pulmonary embolism. Arch Med Sci 2016; 12: 95-100. [CrossRef]

6. Wang F, Hu S, Ding Y, Ju X, Wang L, Lu Q, et al. Neutrophil-to-Lymphocyte Ratio and 30-Day Mortality in Patients with Acute Intracerebral Hemorrhage. J Stroke Cerebrovasc Dis 2016; 25: 182-7. [CrossRef]

7. Wasilewski J, Pyka Ł, Hawranek M, Osadnik T, Kurek A, Skrzypek M, et al. Prognostic value of neutrophil to lymphocyte ratio in predicting longterm mortality in patients with ischemic and nonischemic heart failure. Pol Arch Med Wewn 2016; 126: 166-73. [CrossRef]

8. Toprak C, Tabakci MM, Simsek Z, Arslantas U, Durmus HI, Ocal L, et al. Platelet/lymphocyte ratio was associated with impaired myocardial perfusion and both in-hospital and long-term adverse outcome in patients with ST-segment elevation acute myocardial infarction undergoing primary coronary intervention. Postepy Kardiol Interwencyjnej 2015; 11: 288-97. [CrossRef]

9. Koh $\mathrm{CH}$, Bhoo-Pathy $\mathrm{N}, \mathrm{Ng} \mathrm{KL}$, Jabir RS, Tan GH, See MH, et al. Utility of pre-treatment neutrophil-lymphocyte ratio and platelet-lymphocyte ratio as prognostic factors in breast cancer. Br J Cancer 2015; 113: 150-8. [CrossRef]

10. Vaughan-Shaw PG, Rees JR, King AT. Neutrophil lymphocyte ratio in outcome prediction after emergency abdominal surgery in the elderly. Int J Surg 2012; 10: 157-62. [CrossRef]

11. Forget $\mathrm{P}$, Moreau N, Engel H, Cornu O, Boland B, De Kock M, et al. The neutrophil-to-lymphocyte ratio (NLR) after surgery for hip fracture (HF). Arch Gerontol Geriatr 2015; 60: 366-71. [CrossRef]
12. Sedlar M, Kvasnicka J, Krska Z, Tománková T, Linhart A. Early and subacute inflammatory response and long term survival after hip trauma and surgery. Arch Gerontol Geriatr 2015; 60: 431-6. [CrossRef]

13. Zahorec R. Ratio of neutrophil to lymphocyte counts-Rapid and simple parameter of systemic inflammation and stress in critically ill. Bratisl Lek Listy 2001; 102: 5-147.

14. Jilma B, Blann A, Pernerstorfer T, Stohlawetz P, Eichler HG, Vondrovec B, et al. Regulation of adhesion molecules during human endotoxemia. No acute effects of aspirin. Am J Respir Crit Care Med 1999; 159: 857-63. [CrossRef]

15. Yamanaka T, Matsumoto S, Teramukai S, Ishiwata R, Nagai Y, Fukushima $M$. The baseline ratio of neutrophils to lymphocytes is associated with patient prognosis in advanced gastric cancer. Oncology 2007; 73: 21520. [CrossRef]

16. Kaya MG, Akpek M, Lam YY, Yarlioglues M, Celik T, Gunebakmaz O, et al. Prognostic value of neutrophil/lymphocyte ratio in patients with ST-elevated myocardial infarction undergoing primary coronary intervention: A prospective, multicenter study. Int J Cardiol 2013; 168: 1154-9. [CrossRef]

17. Gunaldi M, Goksu S, Erdem D, Gunduz S, Okuturlar Y, Tiken E, et al. Prognostic impact of platelet/lymphocyte and neutrophil/lymphocyte ratios in patients with gastric cancer: a multicenter study. Int J Clin Exp Med 2015; 8: 5937-42.

18. Kahn JH, Magauran B. Trends in geriatric emergency medicine. Emerg Med Clin N Am 2006; 24: 243-60. [CrossRef]

19. Narang AT, Sikka R. Resuscitation of the elderly. Emerg Med Clin N Am 2006; 24: 261-72. [CrossRef]

20. Heron M. Deaths: Leading causes for 2006. Nat Vital Stat Rep 2010; 58: 1.

21. Birnbaumer Diane M. The elder patient. In: Marx John A. Rosen's emergency medicine: concepts and clinical practice. 8th. ed. Philadelphia: ElsevierSounders; 2014: 2351-5.

22. Gürsoy OM, Karakoyun S, Kalçık M, Gökdeniz T, Yesin M, Gündüz S, et al. Usefulness of novel hematologic inflammatory parameters to predict prosthetic mitral valve. Am J Cardiol 2014; 113: 860-4. [CrossRef]

23. Kwon HC, Kim SH, Oh SY, Lee S, Lee JH, Choi HJ, et al. Clinical significance of preoperative neutrophil-lymphocyte versus platelet lymphocyte ratio in patients with operable colorectal cancer. Biomarkers 2012; 17:216-22. [CrossRef]

24. Azab B, Shah N, Akerman M, McGinn Jr JT. Value of platelet/lymphocyte ratio as a predictor of all-cause mortality after non-STelevation myocardial infarction. J Thromb Thrombolysis 2012; 34: 326-34. [CrossRef]

25. Ferroni P, Riondino S, Formica V, Cereda V, Tosetto L, La Farina F, et al. Venous thromboembolism risk prediction in ambulatory cancer patients: clinical significance of plate/lymphocyte ratio and platelet/lymphocyte ratio. Int J Cancer 2015; 136: 1234-40. [CrossRef]

26. Turkmen K, Erdur FM, Ozcicek F, Ozcicek A, Akbas EM, Ozbicer A, et al. Platelet-to-lymphocyte ratio better predicts inflammation than neutrophil-to-lymphocyte ratio in end-stage renal disease patients. Hemodial Int 2013; 17: 391-6. [CrossRef]

27. Neofytou K, Smyth EC, Giakoustidis A, Khan AZ, Cunningham D, Mudan $S$. Elevated platelet to lymphocyte ratio predicts poor prognosis after hepatectomy for liver-only colorectal metastases, and it is superior to neutrophil to lymphocyte ratio as an adverse prognostic factor. Med Oncol 2014; 31: 239. [CrossRef] 